\title{
Covid-19: Does Housing Protect the Elderly in Latin America? Argentina and Colombia Compared with Spain
}

Juan A. Módenes, Centre d'Estudis Demogràfics and Dept. of Geography, Universitat Autònoma de Barcelona (Spain), Mariana Marcos, Universidad de Buenos Aires, Consejo de Investigaciones Científicas y Técnicas, and Universidad Nacional de Tres de Febrero (Argentina), and Diva Marcela García, Pontificia Universidad Javeriana and Universidad Externado de Colombia (Colombia)

Protecting the elderly population in the new Covid -19 paradigm cannot only be entrusted to confinement at home, especially in Latin America. The household structure, housing characteristics and employment activity of co-residents condition the exposure of elderly people to contagion at home. In order to measure the exposure, this number of Perspectives Demogràfiques suggests calculating an indicator that estimates multidimensional residential risk and allows comparison between populations. More than half of the elderly people of Colombia and 35\% in Argentina are overexposed to Covid-19 at home. Demonstrating that the residential risk is very high in Latin America but also significant in Spain, this study shows that minimizing it must be a priority objective in protecting the elderly. This residential risk indicator for COVID-19 can be used to identify the more exposed areas or subpopulations within countries and guide future policy action with regard to pandemics.

\section{THE ELDERLY AND COVID-19 IN LATIN AMERICA}

Covid -19 has had a huge impact among the elderly population, which constitutes the main risk group since they have more severe symptoms and lethality is much higher. As far as Latin America is concerned, the advantage of moderate population ageing in the region will be offset by the higher prevalence of chronic diseases and at younger ages, inequality, smaller chances of social distancing (Acosta, 2020), and spatial concentration of the population in big cities with high levels of segregation.

It is essential to protect the elderly in both current and future coronavirus waves, as long there is no effective cure (Huenchuan, 2020). This protection should consist of containing the primary contagion but, in particular, reducing secondary intrafamily transmission inside the home (Esteve et al, 2020; Mogi, Spijker 2020). In Latin America, deaths caused by secondary contagion could double those caused by primary contact (Esteve et al, 2020). While, in Europe, the greatest impact of the disease has been among institutionalized elderly people, thus revealing the problems with this type of care (Comas-Herrera, Zalakain, 2020), in Latin America, elderly people live in institutions less often but tend to co-reside in complex or intergenerational household structures (Saad, 2005). In these circumstances, it is difficult for people to isolate themselves completely, and there are additional risks introduced by co-residents who must go out to work, frequently in informal and precarious conditions, and with scant possibilities for teleworking.

The high degree of social inequality in Latin America greatly aggravates the risks of contracting Covid-19 (CEPAL, 2020). The residential risks entailed by large households, intergenerational co-residence, poor quality of housing, the need for older people to work, and informal, precarious and low-skilled jobs of co-residents, are intensified in the lowest socioeconomic groups. Making progress in the struggle against the disease will require the

FIGURE 1. Population aged 65 and older according to residential risk of being exposed to COVID-19. Colombia, Argentina and Spain

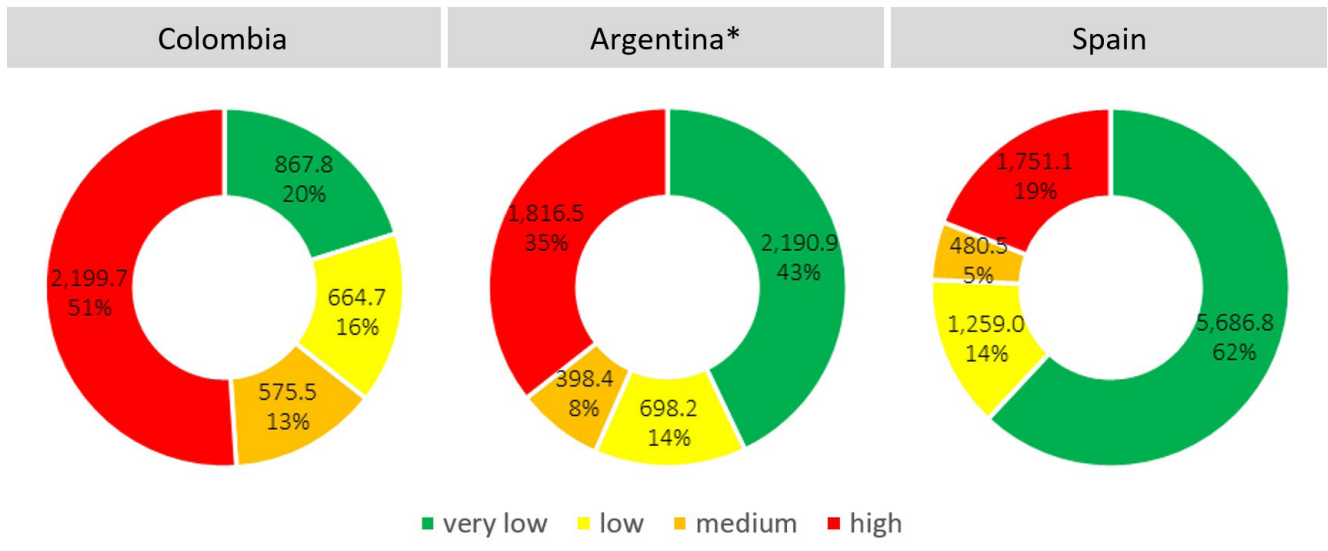

Source: Authors using the Gran Encuesta Integrada de Hogares 2019 (DANE, Colombia), Encuesta Permanente de Hogares 1st semester 2019 and 2010 population projections (INDEC, Argentina), and Encuesta de Condiciones de Vida 2018 (INE, Spain).

*Survey representative of $73 \%$ of elderly adults. Absolute estimates based on projections. 
protection of elderly people in contexts of social vulnerability. In this context, this report aims to assess the general patterns of residential risks for the elderly in Latin America to analyze later on, through other contributions, the inequalities on different scales. Hence, we will explore two representative and different cases, Colombia and Argentina. Then, in order to understand and contextualize the results, we shall compare them with those for Spain.

We suggest a method that makes it possible to synthesize the risks of contagion in the home. The main results (Figure 1) are very revealing. While in Colombia $51 \%$ of elderly people are exposed to a high residential risk of covid-19, this percentage drops to $35 \%$ in Argentina, and 19\% in Spain. On the other hand, only $21 \%$ of elderly Colombians are at very low risk by comparison, with $42 \%$ for Argentina, and 62\% in Spain.

\section{MEASURING THE RESIDENTIAL RISK}

Our indicator allows us to quantify the risk of having domestic contact with the covid-19 disease. It is calculated from a series of quantified household, residential and work indicators related to the protection offered by housing in the case of elderly people (Figure 2). We call this 'residential risk'. For this purpose, measurements are first taken of the distribution of elderly people in accordance with whether they live in one-person or couple households (lower risk), or with other people (higher risk). Second, we compute whether the household lives in overcrowded dwellings (more than two people per bedroom means more risk), and whether there

FIGURE 2. Definition of the levels of residential risk of being exposed to covid-19 in terms of conditions of co-residence, housing and employment

\begin{tabular}{|c|c|c|c|}
\hline $\begin{array}{l}\text { Type of household } \\
\text { and co-residence of } \\
\text { households }\end{array}$ & $\begin{array}{l}\text { Risk by housing } \\
\text { conditions }\end{array}$ & $\begin{array}{l}\text { Probability that } \\
\text { someone cannot do } \\
\text { telework }\end{array}$ & \multirow{17}{*}{$\begin{array}{l}\text { Residential risk } \\
\text { of covid-19 }\end{array}$} \\
\hline \multirow{8}{*}{$\begin{array}{l}\text { one-person } \\
\text { household or couple, } \\
\text { only household in the } \\
\text { dwelling }\end{array}$} & \multirow{4}{*}{$\begin{array}{l}\text { not overcrowded } \\
\text { and with } \\
\text { running water }\end{array}$} & nobody working & \\
\hline & & low & \\
\hline & & medium & \\
\hline & & high & \\
\hline & \multirow{4}{*}{$\begin{array}{l}\text { overcrowded or } \\
\text { without running } \\
\text { water }\end{array}$} & nobody working & \\
\hline & & low & \\
\hline & & medium & \\
\hline & & high & \\
\hline \multirow{8}{*}{$\begin{array}{l}\text { other living } \\
\text { arrangement }\end{array}$} & \multirow{4}{*}{$\begin{array}{l}\text { not overcrowded } \\
\text { and with } \\
\text { running water }\end{array}$} & nobody working & \\
\hline & & low & \\
\hline & & medium & \\
\hline & & high & \\
\hline & \multirow{4}{*}{$\begin{array}{l}\text { overcrowded or } \\
\text { without running } \\
\text { water }\end{array}$} & nobody working & \\
\hline & & low & \\
\hline & & medium & \\
\hline & & high & \\
\hline
\end{tabular}

is a deficit of essential services (no running water means greater risk) or not, which is especially relevant in Latin America. Third, it identifies whether there are working individuals in the home, including elderly people (more risk), or not. And to complete this third dimension, we consider whether the jobs of household members oblige them to leave the home (more risk) or else they can do telework (higher social positions and less risk). The more dimensions of individual risk that are combined, the higher the total residential risk will be.

Sociodemographic surveys from the three countries have been used as sources. The surveys are up to date, they are comparable and they integrate all dimensions discussed. We have used, in the case of Colombia, the Gran Encuesta Integrada de Hogares, 2019 , while for Argentina the sources are the Encuesta Permanente de Hogares (first semester 2019) and the 2010 population projections, and, for Spain, the Encuesta de Condiciones de Vida, 2018 . The universe includes people aged 65 and over at the time of the surveys, who live in private households.

One important research step has been to estimate the probability of an employed person of being able to do telework or, on the contrary, whether this person must work outside the home. We have based our work on Bonavida and Gasparini (2020) who have estimated for each occupational category (2 digits, ISCO code) the probability of being able to be developed from home as telework. We have applied these results to the three countries to calculate the compound probability for each unit of coresidence of finding a person who has to go out to work. This probability tends to increase as more workers are cohabiting in the dwelling and, accordingly, is also positively associated with the size of the domestic group.

By combining all these dimensions, we have arrived at a hierarchical parameterization of the risk to which elderly people are exposed in their homes. Figure 2 presents this "traffic light" account of the risk. If an elderly person lives alone or with a partner, without additional people or households in their home, their housing conditions are adequate, and nobody living in the dwelling works, the risk is very low. Obviously, there will always be a risk of infection, whether it is primary at the beginning of an outbreak or because, in confinement or other stages of 
control, seclusion does not tend to be absolute. Specific activities in the street, like buying provisions can still pose a certain risk. At the other end of the scale, the risk is high when the elderly person lives with other people, especially with someone who must work outside the home, or if this elderly person must go out to work, and if the household is overcrowded, or there is no running water in the dwelling.

According to the data for each of the dimensions of residential risk (Figure 3), in Colombia, 67\% of elderly people share their home with someone other than their partner. Only $38 \%$ live in homes where nobody works, and 52\% share their home with someone who probably must go out to work. Moreover, $14.6 \%$ of elderly people in Colombia live in dwellings with overcrowding or deficient water supply. In Argentina, by contrast, residential risks are lower, but they are also significant: $43 \%$ of elderly people share their home with people other than their partner, and only $54 \%$ of elderly people live in a home where no one works. Some $35 \%$ of elderly people in Argentina cohabit with someone who will most probably have to leave the home to work. And in $5 \%$ of cases, the dwelling has problems of overcrowding or lacks running water.

In Spain, all the parameters are more favorable in relative terms.
Almost two -thirds of the elderly people live in one-person or couple households, and overcrowding is almost completely absent. On the other hand, in $75 \%$ of elderly people's homes anybody works, and in $80 \%$, it is unlikely that someone will have to work outside.

The results point to several lines of conclusion. First, in Latin America, frequent intergenerational co-residence is decisive when calculating the risk. In Spain, the widespread residential independence of elderly people can act as a protective factor within the home. In Latin America, however, the degree of residential independence is related to the social structure. Second, when the elderly cohabit with younger people, there is an increased risk related to employment activity. This risk is aggravated when it is the elderly person who must work (in the absence of formal employment protection or adequate retirement benefits).

Although conditions in Spain are better and its total population is similar to that of Argentina or Colombia, its greater ageing considerably increases the absolute numbers of elderly people at residential risk. Hence, while in Colombia two million people aged 65 or more are living in high-risk conditions, in Argentina the figure is estimated at 1.8 million, and in Spain 1.7 million. The total number of elderly people being exposed to the disease inside
FIGURE 3. Population aged 65 and older, according to conditions of co-residence, housing and employment, Colombia, Argentina and Spain

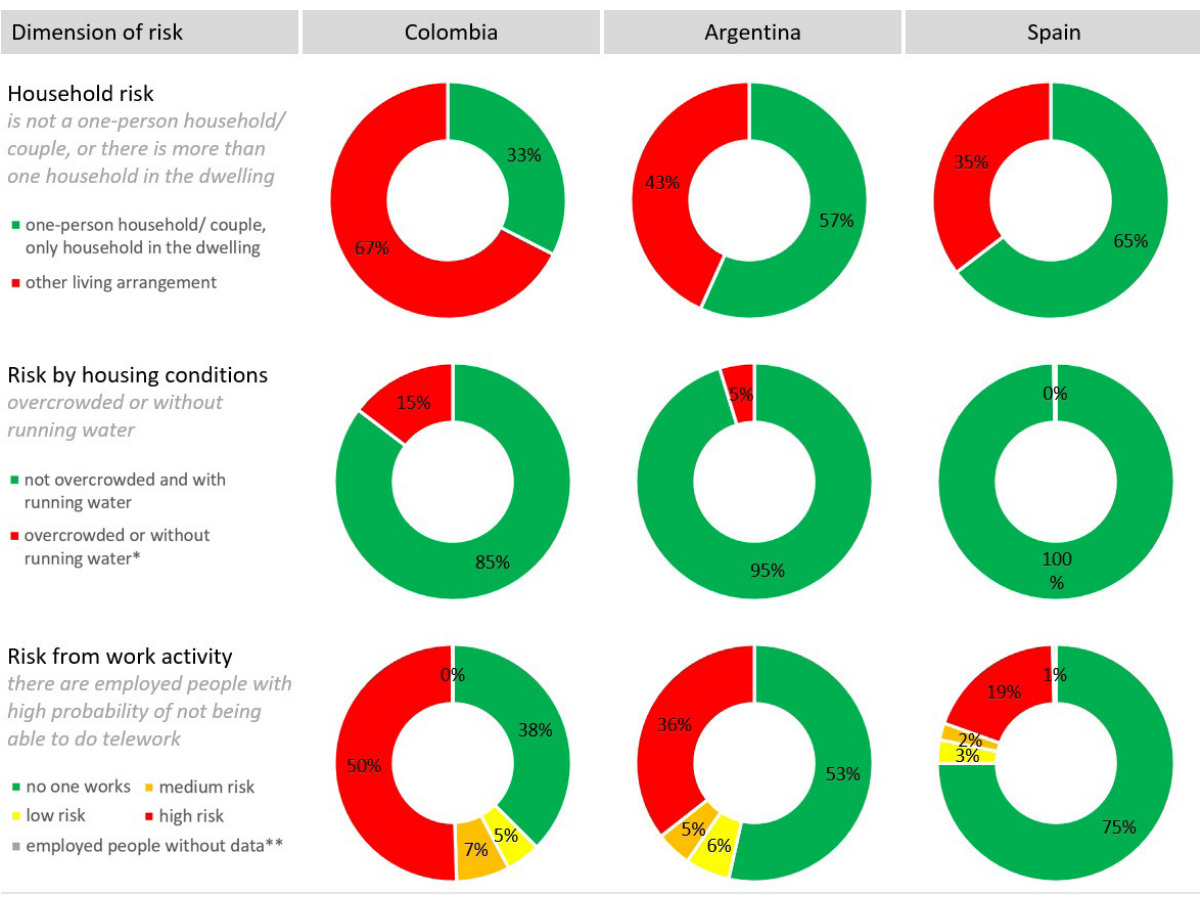

Source: Authors, using the Gran Encuesta Integrada de Hogares 2019 (DANE, Colombia), Encuesta Permanente de Hogares 1st semester 2019 and 2010 population projections (INDEC, Argentina), and Encuesta de Condiciones de Vida 2018 (INE, Spain).

*Argentina; includes people in a villa (shanty town)

** Argentina: in the absence of data on employment, the risk of not being able to do telework is inferred in accordance with the branch of work. the home is high in all three countries under consideration. This is not something specific, but structural.

\section{PROTECTING THE ELDERLY}

We have shown that just trusting in confinement to protect high-risk groups of the population is not a good strategy. The residential risks of elderly people are not negligible in any context, but they are much higher in Latin America. Everyday contact among people, whether they are close or not, is multidimensional and difficult to avoid completely when elderly people do not live alone or with a partner. In this study, we have inquired into some critical dimensions of this social contact: co-residence in the home, housing quality, and the need to work outside the home. And, specifically, we have presented a residential risk indicator based on variables that measure these above mentioned dimensions, and that 
express the vulnerability of elderly people in their domestic context. We have applied this in Colombia and Argentina, which show the specificity of Latin America by comparison with the European country of Spain and, at the same time, demonstrate the internal heterogeneity of the region.

Although the elderly populations tend not to live in overcrowded conditions, the incidence of this problem (even when low) is sufficient to present impediments for general obligatory confinement or the eventual need for individual isolation. Weak social protection in Latin America also forces many older people to keep working, frequently in low-skilled jobs and under informal conditions. If this is not the case, co-residence with younger people and other households frequently brings them into contact with others who must and need to go out to work. Complex patterns of co-residence are associated with more precarious employment situations in the household and greater difficulties in minimizing social contact. In short, any measures to protect older people must anticipate that completely isolating them from people who are less negatively affected but more exposed to covid-19 is not very realistic, and frequently counterproductive. Moreover, the results show that there is a certain polarization of the elderly population between high and low levels of residential risk that will have to be considered.
Our method succeeds in detailing residential risks for other relevant variables, like age, sex, social groups, and geographic levels. If census data is used, it also adds the potential of identifying geographic areas where these risks are more concentrated, in relation to the great heterogeneity of sociodemographic and residential structures of Latin America. At the same time, it turns out to be fundamental, in the longer term, for planning future scenarios to protect this and other groups that are at risk in the eventuality of new episodes of transmission of infectious diseases. And, finally, it allows comparative evaluation of these new challenges with which we are faced.

\section{Bibliography}

Acosta, E. (2020) Seminario Virtual "Epidemias en América Latina: historia y presente". Programa de Población, Facultad de Ciencias Sociales, Udelar, 12-5-2020.

Bonavida, C.; Gasparini, L. (2020) "El Impacto Asimétrico de la Cuarentena". Documentos de Trabajo del CEDLAS, 261, CEDLAS-FCE-UNLP (http://www. cedlas.econo.unlp.edu.ar/wp/no-261/).

CEPAL (2020) El desafio social en tiempos del covid-19. Informe especial (https://repositorio.cepal.org/handle/11362/45527)

Comas-Herrera A.; Zalakain J. (2020) Mortality associated with COVID-19 outbreaks in care homes: early international evidence. LTCcovid.org, International Long-Term Care Policy Network, CPEC-LSE, April (https://ltccovid.org/ wp-content/uploads/2020/04/Mortality-associated-with-COVID-12-April-2. pdf).

Esteve, A.; Permanyer, I.; Boertien, D; Vaupel, J. (2020) "National age and co-residence patterns shape covid-19 vulnerability". medRxiv (https://doi.or g/10.1101/2020.05.13.20100289).
Huenchuan S. (2020) Covid 19: recomendaciones generales para la atención a personas mayores desde una perspectiva de derechos humanos. México: CEPAL (https://repositorio.cepal. org/bitstream/handle/11362/45316/4/ S2000271_es.pdf).

Mogi, R.; Spijker, J. (2020) "The influence of social and economic ties to the spread of COVID-19 in Europe". So cArXiv (https://doi.org/10.31235/osf io/sb8xn).

\section{Citation}

Juan A. Módenes, Mariana Marcos, Diva Marcela García (2020) "Covid-19: Does Housing Protect the Elderly in Latin America? Argentina and Colombia Compared with Spain". Perspectives Demogràfiques, 20: 1-4 (ISSN: 26964228)

ISSN

ISSN 2696-4228

Editors:

Andreu Domingo and Albert Esteve (Centre d'Estudis Demogràfics)

Please address correspondence to:

Juan A. Módenes

jamodenes@ced.uab.es

Mariana Marcos

mmarcos@conicet.gov.ar

Diva Marcela García

diva.garcia@javeriana.edu.co

\section{Acknowledgements:}

This report has been developed in the framework of the $\mathrm{R}+\mathrm{D}+\mathrm{i}$ projects "Comportamientos demográficos y estrategias residenciales: apuntes para el desarrollo de nuevas políticas sociales" (Demographic Behaviour and Residential Strategies: Notes for the Development of New Social Policies, CSO2016-79142-R, Spain) and "Desigualdades microespaciales urbanas" (Urban Microspatial Inequalities, 32/375 A, UNTREF, Argentina). We are grateful to the Centre d'Estudis Demogràfics (CERCA Programme / Generalitat of Catalonia) for its support, and especially the head of the data unit, Tere Menacho. The authors would also like to thank Maru Fernández, Jimena Johan, Florencia Ansaloni and Alejandra Hernández for their help.

\section{Credits}

Graphics: Mariana Marcos Layout: Xavier Ruiz Vilchez

URL

http://ced.uab.es/en/difusion/butlletiperspectives-demografiques

\section{Contact}

Centre d'Estudis Demogràfics. Carrer de Ca n’Altayó, Edifici E2 Universitat Autònoma de Barcelona o8193 Bellaterra / Barcelona Spain

Telephone: +3493581306o Email: demog@ced.uab.cat Web page: www.ced.uab.cat 